\title{
Limites do acesso e do sucesso no ensino superior
}

Thiago Antônio de Oliveira Sá

\author{
HONORATO, Gabriela; HERINGER, Rosana (Org.). Acesso \\ e sucesso no ensino superior: uma sociologia dos \\ estudantes. Rio de Janeiro: 7 Letras: Faperj, 2015. 240 p.
}

Organizada pelas professoras da Universidade Federal do Rio de Janeiro (UFRJ), Gabriela Honorato e Rosana Heringer, a coletânea Acesso e sucesso no ensino superior: uma sociologia dos estudantes segue uma agenda de pesquisa pujante, que tem como sujeitos os estudantes universitários de origens populares, em um contexto nacional de expansão da oferta de vagas no ensino superior. Seu tema geral são os efeitos das políticas para democratização do acesso e da permanência na graduação, como as medidas de expansão de instituições, cursos e vagas e as ações afirmativas. O livro dedica-se fundamentalmente aos estudantes do curso de pedagogia, seus perfis, vivências e estratégias na qualidade de aspirantes a docentes da educação básica, embora contenha trabalhos sobre temas afins. A obra divide-se em duas partes: a primeira apresenta artigos que discutem resultados de pesquisa realizada com ingressantes do curso de pedagogia da UFRJ; a segunda contempla trabalhos sobre acesso, permanência e desempenho no ensino superior brasileiro.

$\mathrm{Na}$ introdução, as organizadoras exploram os resultados da pesquisa, evidenciando que a reserva de vagas proporcionou oportunidade de acesso ao ensino superior público para estudantes cotistas, mas que suas motivações para o ingresso no ensino superior estavam mais associadas ao fato de estudar na UFRJ do que ao curso em si.

No primeiro capítulo, "O acesso ao curso de pedagogia da UFRJ: análise a partir dos ingressantes em 2011-2012", Rosana Heringer avalia que as políticas de democratização ampliam oportunidades para a participação de grupos populares 
no ensino superior. Todavia, subsistem fatores que limitam suas chances de permanência, como dificuldades financeiras, conciliação com o trabalho e pouca participação acadêmica. Além disso, a "escolha" do curso por esses estudantes é realista: dá-se mais pelas expectativas de ingresso do que por desejo. Assim, persistem os desafios para que as intenções de inclusão e democratização das políticas de reserva de vagas não sejam frustradas.

No segundo capítulo, "Origem social e vocação profissional", Maria Lígia de Oliveira Barbosa examina o perfil socioeconômico do corpo discente majoritariamente feminino, confirmando a origem bastante modesta das estudantes. Analisa a escolha da carreira, verificando que o sentido atribuído ao curso por jovens de camadas populares, muitas das vezes, é o de uma opção realista. Conclui-se, que a formação de professores para a educação básica é uma instância de relegação, onde se situam estudantes que não necessariamente queriam estar ali, mas ali foi onde puderam chegar.

Em "Análise dos ingressantes no curso de pedagogia da UFRJ a partir de suas trajetórias no ensino médio", no terceiro capítulo, Carolina Zuccarelli compara as trajetórias das estudantes com base no ensino médio cursado por elas e verifica que boa parte é oriunda de cursos normais. A autora observa que essas normalistas tendem a manter uma relação burocrática com o diploma de pedagogia, isto é, elas privilegiam a obtenção de credenciais para aumento de salário e não a "qualificação" ou o aprimoramento profissional. Depreende-se do texto que, para esse grupo de estudantes, o ensino superior é visto como um protocolo para a mobilidade social.

Gabriela Honorato, no quarto capítulo, "Investigando 'permanência' no ensino superior: um estudo sobre cotistas do curso de pedagogia da UFRJ", salienta a falta de tempo como um problema recorrente desses estudantes, assim, a vivência acadêmica torna-se restrita à frequência às aulas. A autora conclui que é urgente uma pedagogia da "afiliação" que acolha e torne o trabalho acadêmico familiar. O texto aponta para a insensibilidade e a indiferença da universidade quanto à realidade escolar e social de estudantes oriundos de grupos sociais "estreantes" no ensino superior público brasileiro.

O quinto capítulo, "E agora, José?", de Écio Portes, abre a segunda parte do livro. O autor enfatiza a importância de estudos empíricos sobre a trajetória escolar e a permanência dos jovens pobres em universidades públicas, os "estatisticamente improváveis". Fazendo um retrospecto da assistência estudantil no Brasil, Portes chama a atenção para a importância da pesquisa empírica no contexto atual, de expansão do ensino superior público e do aumento do número de vagas. O texto indica uma concepção mais ampla de acesso, que aborde também a permanência, sobretudo quando se trata daqueles que são pioneiros em suas famílias como universitários.

No sexto capítulo, "A distribuição de apoio social e atividades complementares entre estudantes das Ifes por cor e condição de ingresso", Gabriela Honorato traça um quadro da participação em atividades complementares como pesquisa, estágio, extensão e da distribuição de bolsas sociais e acadêmicas entre cotistas e não cotistas nas instituições federais de ensino superior (Ifes). Questionando os reais efeitos da "bolsificação", a autora destaca a importância da participação em atividades complementares para a afiliação institucional e a integração à vida acadêmica. Falta ao texto explicitar se a participação em atividades extracurriculares tem alguma 
correlação com o recebimento de bolsas sociais, para que se observe em que medida esse auxílio facilita (ou não) a afiliação acadêmica ou, ainda, se esta segue sendo um privilégio de classe social. A "bolsificação" influi no pleno engajamento acadêmico?

No sétimo capítulo, "Permanência de bolsistas do ProUni no ensino superior", Clarissa Santos aborda a heterogeneidade entre os bolsistas, os cursos e as instituições. Boa parte desses estudantes são trabalhadores, o que implica dificuldades acadêmicas, de afiliação universitária, de desempenho e de permanência. Além disso, muitas das instituições e dos cursos frequentados por meio de bolsas são "desqualificados". Quanto aos avanços e limites do Programa Universidade para Todos (ProUni), por um lado, esse programa é um mecanismo de inclusão; por outro, de exclusão, pois pode proporcionar uma formação de má qualidade. A partir do texto, atenta-se para o que ainda precisa ser feito para que o ProUni signifique, de fato, democratização do ensino.

Ana Carolina Cardoso e Hustana Vargas assinam o oitavo capítulo: "Invisíveis no campus: sobre a permanência de estudantes de pedagogia e de engenharia mecânica na Universidade Federal Fluminense". Comparando as experiências desses estudantes, elas concluem que, apesar das políticas de inclusão, persistem "artimanhas da exclusão", porque os/as de pedagogia, comparados aos de engenharia, têm frequentemente perfil econômico mais baixo, optam pelo curso por causa da facilidade do ingresso e não pela carreira, e possuem mais bolsas de assistência do que de atividades acadêmicas. Repete-se um ponto já bastante evidenciado pela literatura: a distribuição socialmente determinada dos estudantes pelos cursos, conforme suas respectivas condições socioeconômicas, sendo engenharia e pedagogia, respectivamente, exemplos de cada um dos extremos da hierarquia acadêmica.

No nono capítulo, "Algumas reflexões sobre a identidade do curso de pedagogia", Silke Weber aponta que, em função de mudanças na legislação e das disputas políticas em torno da definição do seu currículo, os cursos de pedagogia no Brasil resultam fragmentados, com conjunto disciplinar disperso, repletos de disciplinas teóricas e de "fundamentos", em detrimento das questões pedagógicas e educacionais concretas. O resultado são cursos de baixa formação específica, de viés ideológico, infensos a mediar teoria e prática e alheios às demandas do mundo do trabalho do pedagogo. A análise apresentada serve de alerta para outros cursos, como ciências sociais e serviço social, nos quais a formação teórica pode ocorrer desconexa da prática profissional de seus graduados.

No décimo capítulo, "Análise do desempenho de cotistas e não cotistas dos cursos de pedagogia do Enade", Márcia de Carvalho traz resultados de comparações entre esses dois grupos de formandos, limitando sua análise às universidades públicas em 2011. A autora demonstra que cotistas e não cotistas não diferem quanto ao tempo levado para concluir o curso, embora não cotistas tenham desempenho ligeiramente superior no Exame Nacional de Desempenho de Estudantes (Enade). Apesar de eventuais dificuldades que cotistas venham a ter em seu desempenho, isso não os impede de se graduar em quatro anos. Contra perspectivas pessimistas e críticas à implementação da política de cotas no ensino superior brasileiro, o texto traz importantes evidências empíricas acerca do desempenho de seus beneficiários, cujo sucesso em concluir os cursos é semelhante ao dos não cotistas. 
Metodologicamente, recomenda-se cautela na leitura dos dados da pesquisa com estudantes, das interpretações feitas e das conclusões tiradas. A amostra foi colhida conforme a disponibilidade para coletá-la, sem observância dos critérios de aleatoriedade, probabilidade e de validação estatística, como nível de confiança e margem de erro. Além disso, as autoras envolvidas na pesquisa hesitam entre o mero exame de dados absolutos e a pretensão de estabelecer generalizações sobre o universo de ingressantes do curso de pedagogia da UFRJ. Quando se limitam aos participantes da amostra, isto é, aos números absolutos, as autoras dispensam a função primordial da amostragem, que é, a partir dos casos selecionados, permitir inferir sobre a população total. Limitar-se à mera comparação de números absolutos não faz sentido porque resulta uma análise em miniatura, descredenciada para oferecer generalizações sobre o universo de pesquisa. Quando arriscam estabelecer generalizações, o fazem sem quaisquer garantias de que elas estão a uma distância aceitável dos parâmetros reais da população total, porque o modo como a amostra foi coletada não o permite. Assim, incorrem em especulações que, em função da própria precariedade amostral, podem indicar conclusões enganosas sobre a população que estudaram. Portanto, como contribuição metodológica, o livro é passível de críticas, por causa da inadequação do trabalho estatístico perante os objetivos de pesquisa traçados.

Contudo, como mapeamento teórico do debate sobre acesso e sucesso no ensino superior brasileiro, a obra é uma importante referência, pois abrange os principais tópicos do debate contemporâneo, recorrendo, para isso, a exaustiva pesquisa bibliográfica, na qual se destaca a atualidade das referências consultadas. A implantação das políticas de cotas, os contornos da expansão recente, os resultados realmente alcançados pelas políticas de inclusão são alguns dos temas descritos e analisados de forma articulada. E todos eles calcados em pesquisa qualitativa com os "novos" estudantes, focando suas vivências, suas motivações para o ensino superior, seus critérios de escolha do curso, suas dificuldades de afiliação,os obstáculos enfrentados pelos estudantes trabalhadores, etc. O livro é referência no estudo da ampliação da oferta de vagas no ensino superior, sobretudo federal.

Por fim, os estudiosos das políticas públicas para o ensino superior e a formação de professores encontrarão na obra os limites da inclusão de "novos" estudantes nas universidades públicas. Fica evidente o menor prestígio dos cursos de formação de professores que, como o de pedagogia, são procurados mais como estratégia de ingresso do que por um interesse genuíno na docência. O livro interessa a pesquisadores da formação de professores, pois retrata a docência como chance realista de acesso ao ensino superior, principalmente em instituições prestigiadas, cuja reputação costuma valer mais do que o curso no qual se ingressou.

Thiago Antônio de Oliveira Sá, mestre pela Universidade Federal de Minas Gerais (UFMG) e doutorando em Sociologia na Universidade Federal de São Carlos (UFSCar), é professor assistente na Universidade Federal de Alfenas (Unifal), Minas Gerais.

oliveirasa@yahoo.com.br 